\title{
COMPARISON OF EFFICACY OF NEURAL THERAPY AND PHYSICAL THERAPY IN CHRONIC LOW BACK PAIN
}

\author{
Nilgun Simsir Atalay ${ }^{1}$, Fusun Sahin ${ }^{1}$, Ali Atalay ${ }^{2}$, Nuray Akkaya ${ }^{1}$ \\ ${ }^{1}$ Pamukkale University Medical School, Department of Physical Medicine and Rehabilitation, Denizli, \\ Turkey. \\ ${ }^{2}$ Denizli State Hospital, Clinic of Orthopedics and Traumatology, Denizli, Turkey. \\ Nilgun Simsir Atalay, Corresponding Author \\ Address: Pamukkale University Medical School, Department of Physical Medicine and Rehabilitation, \\ 20210, Kinikli / Denizli, Turkey. \\ Phone: +902582118129 \\ Fax: +902582118129 \\ E-mail : drnilgunatalay@gmail.com
}

\begin{abstract}
The aim of this prospective study was to evaluate the effects of neural therapy, and physical therapy on level of pain, disability, quality of life, and psychological status in patients with chronic low back pain. Patients admitted to the physical therapy and rehabilitation outpatient clinic with the complaint of low back pain of at least 3 months duration. Group $1(\mathrm{n}=27)$, physical therapy (PT, hotpack, ultrasound, TENS 15 sessions), group $2(\mathrm{n}=33)$, neural therapy (NT, 1:1 mixture of $20 \mathrm{mg} / \mathrm{mL}$ Lidocaine $\mathrm{HCl}$ (Jetokain simplex ${ }^{\circledR}$ ) and saline for 5 sessions. For pain, Visual Analogue Scale (VAS), for disability Roland Morris Disability Questionnaire (RMDQ), for quality-of-life Nottingham-Health-Profile (NHP), for depression, and anxiety, Hospital Anxiety-Depression Scale (HADS) were used before and after the treatment. Mean age was $47.3 \pm 11.32$ years, symptom time was $13.78 \pm 11.98$ months. There were no differences for demographic variables between groups. Significant improvements were detected for VAS, RMDQ, NHP-Pain, NHP-Physical activity, HADS for both of two groups after treatment. In addition to these findings, significant improvements were found for NHP-Energy, NHP-Social isolation in NT group. The differences of pre- and post-treatment values of parameters were evaluated for each group. Although there were no differences for VAS, NHP-sleep, NHP-Emotional reaction, HADS between groups, RMDQ, NHPPain, NHP-Physical activity, NHP-Social isolation were higher in NT than PT before treatment, the improvements for these parameters were better in NT than PT. In conclusion both of NT and PT are effective on pain, function, quality of life, anxiety, and depression in patients with chronic low back pain.
\end{abstract}

Key Words: chronic low back pain, physical therapy, neural therapy

\section{Introduction}

Low back pain (LBP) is currently a common and costly health problem in industrialized communities (Kelsey et al., 1979; Haddad, 1987) and one of the major causes of disability in persons under the age of 45 years (Deyo, 1983; Cunningham et al., 1984; Olsen et al., 1992; Maher, 2004). Approximately 10-20\% of acute LBPs can develop into chronic LBP, which is defined as pain and disability at least 3 months in duration (Maher, 2004). The main goals of treatment in individuals with LBP are to alleviate the pain and improve the functional abilities (DeRosa et al., 1992; Jackson, 2001).

There are various treatment modalities for the management of chronic LBP, including medical treatment, physical therapy, massage, manipulation, traction, and therapeutic exercises. Among them, physical therapy still has an important role in the treatment of chronic LBP. However, due to the diversity and cost of chronic LBP treatments and the lack of randomized and controlled studies on the effectiveness of these treatment modalities, there is no consensus on which treatment modality would be the most appropriate (Mannion et al., 2001; Bentsen et al., 1997; Ross, 2002; Brosseau et al., 2002).

The alleviation of pain by using local anesthetic agents is an ancient tradition and they may be used in functional disorders (Zohmann, 1997). Neural therapy is based on normalizing dysfunctional autonomic nervous system, the part of the peripheral nervous system that is responsible for the involuntary actions in the body such as immune system, cardiovascular system, endocrine system and also the healing process (Harris, 2010).

The main purpose of the present study was to evaluate the effectiveness of neural therapy and physical therapy on the pain, disability, quality of life, and psychological status in patients with chronic LBP.

\section{Materials and Methods}

The study included all patients admitted to the physical therapy and rehabilitation outpatient clinic with the complaint of low back pain of at least 3 months duration. The patients were classified into two groups: those scheduled for 
physical therapy (Group 1) and those in whom previous physical therapy programme failed to alleviate the symptoms (Group 2). All patients were informed about the aim of the study and those accepting to participate in the study were included. Informed consent was taken from the patients. The sociodemographic characteristics of the patients were recorded. The exclusion criteria were as follows: low back pathologies that can result in neurological defects in the lower extremity, malign diseases, connective tissue or inflammatory rheumatic diseases, benign or malign tumors in lumbar region, the infection localized to the lumbar region or systemic infection, previous spinal fractures, the diagnosis and treatment of a psychiatric disorder, and illiterate patients.

Physical therapy (PT) patients (Group 1) were those who were examined in the outpatient clinic, and scheduled for physical therapy program. Patients who had exclusion criteria were not included in study. The physical therapy programme included superficial heating (hot packs), deep heating (ultrasound, US) and analgesic stimulation (Transcutaneous electrical nerve stimulation, TENS) to the lumbar region. The superficial heating with hot packs and deep heating with US were applied to the lumbar region for 20 and $10 \mathrm{~min}$, respectively. The patients received the continuous US at a frequency of 1 $\mathrm{MHz}$ and an intensity of $1.5 \mathrm{~W} / \mathrm{cm}^{2}$. The transducer head was slowly slid with circular movements over the paravertebral lumbar region. Finally, the conventional TENS $(30-40 \mathrm{~Hz})$ was applied to the patients for $20 \mathrm{~min}$. The patients also received an exercise programme that included mobilization, stretching and strengthening exercises. The physical therapy program was applied 5 times a week for 3 weeks.

Neural therapy (NT) patients (Group 2) were those who were referred to our outpatient clinic due to the failure of previous physical therapy to alleviate the symptoms, and accepted injections were included in this group. This group of patients received local injection treatment $\left(1: 1\right.$ mixture of $20 \mathrm{mg} / \mathrm{mL}$ Lidocaine $\mathrm{HCl}$ (Jetokain simplex ${ }^{\circledR}$ and saline) for 5 sessions. We preferred Lidocaine instead of Novocaine which is much more commonly used in NT, because of there is no Novocaine in Turkey. The first 3 sessions were 3 days apart, followed by 2 sessions per week. The NT included a local treatment to the patients with muscle spasm and trigger-points in the lumbar region, a segmental treatment of the lumbar spine with the quaddle, and an interference fields (eg, umbilicus, and scars resulting from vaccination and surgical operations) treatment. All interference fields which were detected, were injected in each patient. Segmental quaddle was executed in every seances, interference fields were applied at only second seance. Quaddles are the intradermal injections that are injected around the painfull vertebral segments. According to neural therapy concept, scars are the structures that cause blockage in the transmission network of vegetative system with interfering the integrity of the skin. Injections of local anesthetics into scars are believed that cause improvements in the transmission network. Additional quaddles were set over some acupuncture points whenever needed. According to neural therapy concept, local anesthetic injections were done in concerned acupuncture points of the systems that need to be regulated based on patients' history (Nazlikul, 2010a). Patients were also asked to continue their previous exercise therapy (mobilization, stretching and strengthening exercises).

Before the commencement and after the termination of the treatment (at the end of week 3), all subjects were evaluated by using Visual Analogue Scale for pain, Roland Morris Disability Questionnaire for the function, Nottingham Health Profile for quality of life, and Hospital Anxiety and Depression Scale for anxiety and depression.

Pain severity: Visual Analogue Scale (VAS) measures the severity of pain. The scale is $10 \mathrm{~cm}$ in length and has different descriptors at each end on a horizontal line $(0=$ no pain and $10=$ worst pain). The patient marks on the line the point that represents his/her pain severity. The VAS score is determined by measuring the distance in centimeters from the lowest end of the line to the point that the patient marks.

Function: The Roland Morris Disability Questionnaire (RMDQ) was used to assess the physical disability in activities of daily living (ADLs) due to LBP. The patient was asked to answer all items beginning with the phrase of "because of my low back pain" as yes/no. Total score for 24 items was calculated by giving 1 point for the answers of "yes and 0 point for the answers of "no". For this questionnaire, a higher score indicates greater disability (Roland et al., 1983). The Turkish version of the questionnaire was tested for the validity (Kucukdeveci et al., 2001).

Quality of life: The Nottingham Health Profile (NHP) is a scale intended to assess a patient's emotional, social and physical activity levels. The scale consists of 38 questions in 6 subcategories including pain, emotional reaction, energy level, sleep, social isolation and physical activity. Scores for each subgroup range from 0 (no problem) to 100 (all problems listed were present) (Hunt et al., 1981). The Turkish version of the scale was tested for the validity (Kucukdeveci et al., 2000).

Anxiety and depression: The Hospital Anxiety and Depression Scale (HADS) is a self assessment tool that determines the risk and level of anxiety and depression as well as assessesing the changes in severity. The scale consists of 14 items, with 7 items (odd numbers) reflecting the anxiety and other 7 (even numbers) reflecting the depression. Each item was answered by the patient on a 4-point $(0-3)$ Likert scale. The Turkish version of the scale was tested for the validity and reliability (Aydemir et al., 1997).

Statistical analysis was done by using SPSS for Windows 17.0 software and $p<0.05$ was considered significant. Descriptive statistics and chi square tests were used for demographic and categorical data. Paired t- test was used for comparison of the results of before and after treatments within group evaluation. Student t-test was used for comparison of intergroup.

\section{Results}

A total of 60 patients (32 females $(53.3 \%)$ and 28 males $(46.7 \%)$ with a mean age of $47.3 \pm 11.32$ years were included to the study. The mean duration of the symptoms was $13.78 \pm 11.98$ months. The sociodemographic characteristics of these patients are shown in Table 1. There were no significant differences in age, gender, educational level and symptom duration between the groups $(\mathrm{p}>0.05)$. 
Atalay et al., Afr J Tradit Complement Altern Med. (2013) 10(3):431-435

http://dx.doi.org/10.4314/ajtcam.v10i3.8

Table 1: The sociodemographical characteristics of the patients

\begin{tabular}{|l|l|l|l|}
\hline & Physical therapy group & Neural therapy group & $\mathrm{p}$ \\
\hline Age (year) & $44.86 \pm 11.47$ & $50.3 \pm 10.58$ & 0.063 \\
\hline BMI $\left(\mathrm{kg} / \mathrm{m}^{2}\right)$ & $28.86 \pm 4.73$ & $28.22 \pm 2.6$ & 0.728 \\
\hline Disease duration (months) & $11.73 \pm 13.22$ & $16.29 \pm 9.94$ & 0.143 \\
\hline Sex & $16(48.5)$ & $16(59.3)$ & \\
Female (n, \%) & $17(51.5)$ & $11(40.7)$ & 0.405 \\
Male (n, \%) & \multicolumn{2}{|l}{} \\
\hline $\begin{array}{l}\text { Marital status } \\
\text { Single }\end{array}$ & $4(12.1)$ & $1(3.7)$ & \multirow{2}{*}{0.241} \\
Married & $29(87.9)$ & $26(96.3)$ & \\
\hline
\end{tabular}

BMI: Body mass index

Table 2: Comparison of pre- and post-treatment scores of pain, function, quality of life, anxiety, and depression

\begin{tabular}{|c|c|c|c|}
\hline & Physical therapy group & $\begin{array}{l}\text { Neural therapy } \\
\text { group }\end{array}$ & $\mathbf{p}^{*}$ \\
\hline $\begin{array}{l}\text { VAS } \\
\text { Pretreatment } \\
\text { Posttreatment }\end{array}$ & $\begin{array}{l}7.85 \pm 2.28 \\
4.79 \pm 3.54\end{array}$ & $\begin{array}{l}7.4 \pm 2.24 \\
3.56 \pm 2.68\end{array}$ & $\begin{array}{l}0.455 \\
0.131\end{array}$ \\
\hline $\mathrm{p}^{* *}$ & 0.001 & 0.001 & \\
\hline $\begin{array}{l}\text { RMDQ } \\
\text { Pretreatment } \\
\text { Posttreatment }\end{array}$ & $\begin{array}{l}14.9 \pm 4.98 \\
9.76 \pm 6.75 \\
\end{array}$ & $\begin{array}{l}18.07 \pm 4.07 \\
9.85 \pm 4.89 \\
\end{array}$ & $\begin{array}{l}\mathbf{0 . 0 1} \\
0.95 \\
\end{array}$ \\
\hline $\mathrm{p}^{* *}$ & 0.001 & 0.001 & \\
\hline $\begin{array}{l}\text { NHP-Pain } \\
\text { Pretreatment } \\
\text { Posttreatment }\end{array}$ & $\begin{array}{l}64.02 \pm 21.37 \\
38.64 \pm 29.54\end{array}$ & $\begin{array}{l}86.11 \pm 17.79 \\
44.9 \pm 28.0\end{array}$ & $\begin{array}{l}\mathbf{0 . 0 0 1} \\
0.406\end{array}$ \\
\hline $\mathrm{p}^{* *}$ & 0.001 & 0.001 & \\
\hline $\begin{array}{l}\text { NHP-Physical activity } \\
\text { Pretreatment } \\
\text { Posttreatment }\end{array}$ & $\begin{array}{l}41.29 \pm 19.13 \\
29.92 \pm 20.24 \\
\end{array}$ & $\begin{array}{l}56.02 \pm 20.9 \\
31.94 \pm 17.79 \\
\end{array}$ & $\begin{array}{l}\mathbf{0 . 0 0 6} \\
0.686 \\
\end{array}$ \\
\hline $\mathrm{p}^{* *}$ & 0.001 & 0.001 & \\
\hline $\begin{array}{l}\text { NHP-Energy level } \\
\text { Pretreatment } \\
\text { Posttreatment }\end{array}$ & $\begin{array}{l}43.42 \pm 42.88 \\
33.32 \pm 36.32 \\
\end{array}$ & $\begin{array}{l}65.43 \pm 33.96 \\
51.84 \pm 37.37 \\
\end{array}$ & $\begin{array}{l}\mathbf{0 . 0 3} \\
0.057\end{array}$ \\
\hline $\mathrm{p}^{* *}$ & 0.057 & 0.003 & \\
\hline $\begin{array}{l}\text { NHP-Sleep } \\
\text { Pretreatment } \\
\text { Posttreatment }\end{array}$ & $\begin{array}{l}27.27 \pm 25.89 \\
26.06 \pm 28.93\end{array}$ & $\begin{array}{l}36.29 \pm 26.62 \\
30.37 \pm 23.77\end{array}$ & $\begin{array}{l}0.19 \\
0.537\end{array}$ \\
\hline $\mathrm{p}^{* *}$ & 0.721 & 0.073 & \\
\hline $\begin{array}{l}\text { NHP-Social isolation } \\
\text { Pretreatment } \\
\text { Posttreatment }\end{array}$ & $\begin{array}{l}9.69 \pm 20.69 \\
10.3 \pm 22.43 \\
\end{array}$ & $\begin{array}{l}28.15 \pm 29.49 \\
20.74 \pm 26.88 \\
\end{array}$ & $\begin{array}{l}\mathbf{0 . 0 0 9} \\
0.106 \\
\end{array}$ \\
\hline $\mathrm{p}^{* *}$ & 0.744 & 0.039 & \\
\hline $\begin{array}{l}\text { NHP-Emotional reaction } \\
\text { Pretreatment } \\
\text { Posttreatment }\end{array}$ & $\begin{array}{l}19.85 \pm 26.3 \\
16.82 \pm 23.74\end{array}$ & $\begin{array}{l}35.39 \pm 35.29 \\
29.21 \pm 31.76\end{array}$ & $\begin{array}{l}0.064 \\
0.089\end{array}$ \\
\hline $\mathrm{p}^{* *}$ & 0.212 & 0.113 & \\
\hline $\begin{array}{l}\text { Hospital Depression Scale } \\
\text { Pretreatment } \\
\text { Posttreatment }\end{array}$ & $\begin{array}{l}6.06 \pm 5.47 \\
5.55 \pm 4.87\end{array}$ & $\begin{array}{l}8.33 \pm 5.0 \\
7.78 \pm 4.5\end{array}$ & $\begin{array}{l}0.102 \\
0.073\end{array}$ \\
\hline $\mathrm{p}^{* *}$ & 0.001 & 0.026 & \\
\hline $\begin{array}{l}\text { Hospital Anxiety Scale } \\
\text { Pretreatment } \\
\text { Posttreatment }\end{array}$ & $\begin{array}{l}7.76 \pm 2.82 \\
6.73 \pm 2.68\end{array}$ & $\begin{array}{l}8.26 \pm 4.54 \\
7.03 \pm 3.4\end{array}$ & $\begin{array}{l}0.619 \\
0.695\end{array}$ \\
\hline $\mathrm{p}^{* *}$ & 0.001 & 0.004 & \\
\hline
\end{tabular}

VAS: Visual Analogue Scale, RMDQ: The Roland Morris Disability Questionnaire,

NHP: The Nottingham Health Profile, $\mathrm{p}^{*}$ :intergroups $\mathrm{p}^{* *}$ :intragroups 
Atalay et al., Afr J Tradit Complement Altern Med. (2013) 10(3):431-435

http://dx.doi.org/10.4314/ajtcam.v10i3.8

Table 3: Comparison of the differences of pre- and post-treatment scores between groups

\begin{tabular}{|l|l|l|l|}
\hline & $\begin{array}{l}\text { Physical therapy } \\
\text { group }\end{array}$ & $\begin{array}{l}\text { Neural therapy } \\
\text { group }\end{array}$ & $\mathbf{p}$ \\
\hline VAS & $-3.06 \pm 2.42$ & $-3.85 \pm 2.61$ & 0.229 \\
\hline RMDQ & $-5.15 \pm 4.79$ & $-8.22 \pm 5.23$ & $\mathbf{0 . 0 2 1}$ \\
\hline NHP-Pain & $-25.38 \pm 24.1$ & $-41.2 \pm 29.99$ & $\mathbf{0 . 0 2 7}$ \\
\hline NHP-Physical activity & $-11.36 \pm 13.39$ & $-24.07 \pm 19.28$ & $\mathbf{0 . 0 0 4}$ \\
\hline NHP-Energy level & $-10.1 \pm 29.45$ & $-13.59 \pm 21.21$ & 0.609 \\
\hline NHP-Sleep & $-1.21 \pm 19.32$ & $-5.93 \pm 16.47$ & 0.32 \\
\hline NHP-Social isolation & $0.6 \pm 10.59$ & $-7.4 \pm 17.67$ & $\mathbf{0 . 0 4 5}$ \\
\hline NHP-Emotional reaction & $-3.03 \pm 13.68$ & $-6.18 \pm 19.58$ & 0.467 \\
\hline Hospital Depression Scale & $-0.52 \pm 0.76$ & $-0.56 \pm 1.22$ & 0.881 \\
\hline Hospital Anxiety Scale & $-1.03 \pm 0.88$ & $-1.22 \pm 1.99$ & 0.644 \\
\hline
\end{tabular}

VAS: Visual Analogue Scale, RMDQ: The Roland Morris Disability Questionnaire,

NHP: The Nottingham Health Profile

In pre-treatment assessments, while VAS, NHP-sleep, NHP-emotional reaction and HADS scores were not significantly different between groups ( $>00.05)$, RMDQ, NHP-pain, NHP-physical activity, NHP-energy level and NHPsocial isolation scores were significantly higher in NT group compared to the PT group $(p<0.05)$ (Table 2$)$.

After the completion of the treatment, VAS, RMDQ, NHP-pain, NHP-physical activity and HADS scores in both NT and PT groups were significantly improved compared to the pre-treatment scores $(p<0.05)$. The NT group showed significant improvements also in the scores of NHP-energy level and NHP-social isolation $(\mathrm{p}<0.05)($ Table 2$)$.

None of the post-treatment scores differed between the two group of patients $(\mathrm{p}>0.05)$ (Table 2$)$.

In the comparison of pre- and post-treatment scores, pre-treatment scores of RMDQ, NHP-pain, NHP-physical activity and NHP-social isolation were significantly higher in NT group compared to the PT group, while these scores were significantly better improved in NT group compared to PT group after the completion of treatment $(\mathrm{p}<0.05)($ Table 3$)$.

\section{Discussion}

The results of the present study comparing the short-term effects of physical therapy and neural therapy on pain, disability, QOL and psychological status of patients with chronic LBP demonstrate that both treatment modalities resulted in significant improvements in pain, disability, the pain and physical activity subcategories of QOL, and anxiety and depression. Energy level and social isolation subcategories of QOL significantly improved only in NT group. Pre-treatment disability and the pain, physical activity and social isolation subscores of QOL were significantly higher in NT group compared to the PT group, while post-treatment scores were significantly better improved in NT group compared to PT group.

It was suggested that the illness and dysfunction are always associated with the dysfunction of autonomic nervous system that results in decreased blood supply to a particular tissue and impairment of healing process. This mechanism has a particular importance in musculoskeletal system, because adequate blood supply to the injured area is crucial in healing process. Accordingly, any injury to the autonomic nervous system that decreases blood flow to the lumbar region results in poor healing (Harris, 2010).

Neural therapy is a holistic therapy that affects the neurovegetative system and uses local anesthetic agents. Every cell in the body represents a potassium battery with a potential of $40-90 \mathrm{mV}$. The cell becomes depolarized with every stimulus. Normally, the oxygen metabolism of the cell improves this membrane potential by charging the cell and normalizing the voltage. Successive or exceedingly strong stimuli results in a constantly low membrane potential and the cell is often no longer able to normalize this reduced potential on its own. The stimulation of the neurovegetative system through injection of local anesthetics to the correspondent regions loads cells with energy and normalizes the voltage. Thus, neurovegetative system returns to its normal function and the healing factors such as tissue healing and adequate blood supply lead to the recovery of disease (Nazlikul, 2010b).

To our knowledge, this is the first study to compare the effectiveness of physical therapy and neural therapy in chronic LBP. The literature lacks sufficient data on this issue. In the study comparing the short- and long-term outcomes of acupuncture and neural therapy, the age was significantly greater, symptom duration was significantly longer and the percentage of subjective recovery tended to be higher in the neural therapy group compared to the acupuncture group (Barbagli et al., 2003). In the present study, we combined the neural therapy with acupuncture and found significant improvements in outcome measures.

The main goals in the treatment of chronic LBP are pain alleviation, prevention of physical and the mental disabilities, and achievement of improvements in QOL. Uncontrolled studies have demonstrated the effects of various physical therapy modalities on chronic LBP (Mannion et al., 2001). However, because the number of randomized controlled studies investigating the effect of these therapies is limited, there is no consensus on which modalities are more effective in the management of chronic LBP (Mannion et al., 2001; Bentsen et al., 1997; Ross, 2002; Brosseau et al., 2002). Most of the studies in this field combined various physical therapy agents with the exercise therapy and found significant short- and medium-term improvements in the parameters studied.

Patients suffering from chronic LBP have showed significant improvements in pain, disability, general health status and depression severity with a combined home exercise and physical therapy (Hotpack+US+TENS) programme, while those 
http://dx.doi.org/10.4314/ajtcam.v10i3.8

who performed the home exercise therapy alone had no significant improvement, except for the pain (Koldaş Doğan et al., 2008). Another study of patients with chronic LBP showed statistically significant improvements in pain and disability scores with a 10 sessions of physical therapy program (Hotpack+US+exercise) (Borman et al., 2003). Durmus et al. 2010 also reported that a therapy programme which included Hotpack+US+exercise treatments ( 5 times weekly for 3 weeks) resulted in significant improvements in pain, disability, QOL and depression scores. Accordingly, the exercise therapy combined with physical therapy showed significant correlations with pain, function, QOL, anxiety and depression scores in our study.

The major limitations of the present study are that it has a non-randomized and uncontrolled design, and provides only short-term outcomes. Therefore, one cannot assume that both therapy modalities result in better outcomes than control. Also, because many of the pre-treatment scores were worse in NT group than PT group, it is not possible to compare the two homogeneous groups. However, the present study may have significant clinical implications, because it evaluated the effectiveness of these two treatment modalities, partially compared them and at least to our knowledge, is the first study in this matter of subject.

\section{Conclusions}

Future randomized controlled studies on the short-, medium-, and long-term outcomes and cost-effectiveness of these treatment modalities as well as studies on the effects of them on QOL and social problems such as labour loss would give new insights into the management of patients with chronic low back pain.

\section{References}

1.Aydemir, Ö., Güvenir, T., Küey, L., Kültür, S. (1997). Hastane Anksiyete ve Depresyon Ölçeği Türkçe formunun geçerlilik ve güvenilirliği. Türk. Psik. Dergisi., 8:280-287.

2. Barbagli, P., Bollettin, R., Ceccherelli, F. (2003). Acupuncture (dry needle) versus neural therapy (local anesthesia) in the treatment of benign back pain. Immediate and long-term results. Minerva Med. 94:17-25.

3. Bentsen, H., Lindgärde, F., Manthorpe, R. (1997). The effect of dynamic strength back exercise and/or a home training program in 57year-old women with chronic low back pain. Results of a prospective randomized study with a 3-year follow-up period. Spine. 22:14941500 .

4. Borman, P., Keskin, D., Bodur, H. (2003). The efficacy of lumbar traction in the management of patients with low back pain. Rheumatol. Int. 23:82-86,

5. Brosseau, L., Milne, S., Robinson, V., Marchand, S., Shea, B., Wells, G., Tugwell P. (2002). Efficacy of the transcutaneous electrical nerve stimulation for the treatment of chronic low back pain: a meta-analysis. Spine. 27:596-603.

6. Cunningham, LS., Kelsey, JL. (1984). Epidemiology of musculoskeletal impairments and associated disability. Am. J. Public. Health. 74:574-579.

7. DeRosa, CP., Porterfield, JA. (1992). A physical therapy model for the treatment of low back pain. Phys. Ther. 72:261-269.

8. Deyo, RA. (1983). Conservative therapy for low back pain. Distinguishing useful from useless therapy. JAMA. 250:1057-1062.

9. Durmus, D., Akyol, Y., Cengiz, K., Terzi, T., Cantürk, F. (2010). Effects of therapeutic ultrasound on pain, disability, walking performance, quality of life, and depression in patients with chronic low back pain: a randomized, placebo controlled trial. Turk. J. Rheumatol. 25:82-87.

10. Haddad, GH. (1987). Analysis of 2932 workers' compensation back injury cases. The impact on the cost to the system. Spine. 12:765769.

11. Harris, GR. (2010). Effective treatment of chronic pain by the integration of neural therapy and prolotherapy. Journal of Prolotherapy. 2:377-386.

12. Hunt, SM., McKenna, SP., McEwen, J., Williams, J., Papp, E. (1981). The Nottingham Health Profile: subjective health status and medical consultations. Soc. Sci. Med. A. 15:221-229.

13. Jackson, DA. (2001). How is low back pain managed? Retrospective study of the first 200 patients with low back pain referred to a newly established community-based physiotherapy department. Physiotherapy. 87:573-581.

14. Kelsey, JL., White, AA, 3rd., Pastides, H., Bisbee, GE, Jr. (1979). The impact of musculoskeletal disorders on the population of the United States. J. Bone. Joint. Surg. Am. 61:959-964.

15. Koldaş, Doğan, S., Sonel, Tur, B., Kurtaiş, Y., Atay, MB. (2008) Comparison of three different approaches in the treatment of chronic low back pain. Clin. Rheumatol. 27:873-881.

16. Kücükdeveci, AA., McKenna, SP., Kutlay S., Gürsel, Y., Whalley, D., Arasil, T. (2000). The development and psychometric assessment of the Turkish version of the Nottingham Health Profile. Int. J. Rehabil. Res. 23:31-38.

17. Küçükdeveci, AA., Tennant, A., Elhan, AH., Niyazoglu, H. (2001). Validation of the Turkish version of the Roland Morris Disability Questionnaire for use in low back pain. Spine. 26:2738-2743.

18. Maher, CG. (2004). Effective physical treatment for chronic low back pain. Orthop. Clin. North. Am. 35:57-64

19. Mannion, AF., Müntener, M., Taimela, S., Dvorak, J. (2001). Comparison of three active therapies for chronic low back pain: results of a randomized clinical trial with one-year follow-up. Rheumatology (Oxford). 40:772-778.

20. Nazlıkul, H. (2010a). Nöralterapi teknikleri ve bozucu alan terapisi. Nazlıkul, H. ed. Nöralterapi. Nobel Tip Kitabevleri. 165-172.

21. Nazlıkul, H. (2010b) Nöralterapi. Nazlıkul, H. ed. Nöralterapi. Nobel Tıp Kitabevleri. 137-157.

22. Olsen, TL., Anderson, RL., Dearwater, SR., Kriska, AM., Cauley, JA., Aaron, DJ., LaPorte, RE. (1992). The epidemiology of low back pain in an adolescent population. Am. J. Public. Health. 82:606-608.

23. Roland, M., Morris, R. (1983). A study of the natural history of back pain. Spine. 8:141.

24. Ross, MD. (2002). Physical therapy and changes in disability for patients with low back pain. Mil. Med. 167:662-665.

25. Zohmann, A. (1997). Basis and use of neural therapy in diagnosis and treatment. Schweiz. Arch. Tierheilkd. 139:117-125. 